\title{
INTERACTIVE MEDIA TO LEARN IDENTIFYING PATTERNS AND CALCULATING GEOMETRY OBJECTS (CASE STUDY: TK ABA SURYA MELATI, YOGYAKARTA)
}

\author{
Dwi Nugraheny ${ }^{1}$, Arry Dwi Setiawan ${ }^{2}$ \\ Program Studi Teknik Informatika \\ Sekolah Tinggi Teknologi Adisutjipto \\ Jl. Janti Blok R Adisucipto Yogyakarta \\ 1)henynug@gmail.com, ${ }^{2)}$ arrydwisetiawan@ gmail.com
}

\begin{abstract}
Interactive learning media is the media more effectively so that the user can feel the learn more practical yet fun and stimulating for users desirous of learning. The pattern is the process of recognizing an object based on data that already exists to distinguish various patterns with different size and geometry of each pattern is obtained. The purpose of this thesis was to design an interesting learning media and interactive, in particular to facilitate the child TK Aba Surya Melati get to learn identifying pattern and calculating geometry objects. Based on testing performed, the results obtained to learn identifying pattern $80 \%$ and calculating geometry objects is $65 \%$.
\end{abstract}

Keywords : Identifying Patterns, Calculating, Interactive Media, Geometry Objects.

\section{Latar Belakang Masalah}

Taman Kanak-kanak (TK) merupakan salah satu pendidikan prasekolah yang menyediakan program pendidikan dini bagi anak usia dini (usia 4-6 tahun). Menurut Pendidikan Prasekolah Bab I pasal 1 ayat (1) menyebutkan Pendidikan prasekolah adalah pendidikan untuk membantu pertumbuhan dan perkembangan jasmani dan rohani anak didik di luar lingkungan keluarga sebelum memasuki pendidikan dasar, yang diselenggarakan di jalur pendidikan sekolah atau dijalur pendidikan luar sekolah, [1].

Menurut [2], berpendapat bahwa kemampuan matematika yang dimiliki anak TK dalam konsep bentuk, warna, ukuran dan pola (Matrik Kurikulum 2010) anak sudah dapat mengklasifikasikan benda berdasarkan bentuk atau warna atau ukuran, mengklasifikasikan benda ke dalam kelompok yang sama atau kelompok yang sejenis atau kelompok yang berpasangan, mengenal pola $\mathrm{AB}-\mathrm{AB}$ dan $\mathrm{ABC}-\mathrm{ABC}$, mengurutkan benda berdasarkan lima variasi ukuran atau warna.

Pola merupakan proses mengenali suatu objek berdasarkan data-data yang sudah ada untuk membedakan macam-macam pola dengan ukuran dan bentuk yang berbeda dari setiap pola yang didapatkan. Sedangkan pengertian menghitung itu sendiri berarti berhitung yang mana terdapat penjumlahan, pengurangan, pembagian, perkalian. Dari setiap perhitungan terdapat cara perhitungan sehingga mendapatkan hasil yang akurat dan benar.

Menurut[3], Media Pembelajaran merupakan bagian integral dari keseluruhan sistem dan proses pembelajaran, artinya media pembelajaran merupakan unsur yang sangat penting dan menentukan terhadap kegiatan pembelajaran. Menurut[4], Pembelajaran Interaktif yakni memiliki banyak keunggulan dari metode belajar konvensional pada anak usia 1-5 tahun, tampilan animasi interaktif dalam dunia pendidikan dapat membantu siswa pada penyampaian materi dan lebih komunikatif sehingga dapat lebih mudah mengingat materi pembelajarannya.'Pada pembuatan media pembelajaran interaktif ini, akan dilakukan pengenalan pola dan belajar menghitung bangun datar 2D (2 Dimensi) secara tepat dan menyenangkan sehingga anak tidak akan merasa bosan untuk belajar mengenal pola dan menghitung.

\section{Metodologi Pembuatan Media Pembelajaran Interaktif}

Metodologi yang digunakan dalam pembuatan media pembelajaran interaktif yaitu :

1. Metode Pengumpulan Data 
a. Melakukan studi literasi dengan mencari referensi dari buku dan internet yang terkait dengan anak TK.

b. Melakukan wawancara dengan menanyakan kepada guru TK Aba Surya Melati.

2. Analisa Kebutuhan Sistem

Analisa yang dibutuhkan meliputi analisa kebutuhan perangkat lunak dan perangkat keras, serta analisa kebutuhan data.

3. Perancangan Sistem

Perancangan sistem terdiri dari perancangan, alur data, alur cerita, perancangan antarmuka.

4. Implementasi Sistem

Implementasi sistem merupakan penerapan perancangan sistem yang telah dibuat kedalam software Adobe Flash Professional CS6 dan bahasa pemrograman Java.

5. Pengujian

Pengujian dilakukan langsung ke pengguna yakni anak TK Aba Surya Melati di Brajan, Tamantirto, Kasihan Bantul. Penilaian dilakukan berdasarkan nilai dan kemampuan anak mengenal pola dan belajar menghitung bangun datar melalui pengunaan aplikasi. Pengujian dilakukan minimal pada 30 anak TK Aba Surya Melati.

\subsection{Landasan Teori}

Media Pembelajaran Interaktif merupakan media yang lebih efektif agar pengguna dapat merasakan belajar yang lebih praktis namun menyenangkan serta merangsang pengguna untuk berkeinginan belajar yang kuat. Menurut [5], berpendapat bahwa multimedia adalah suatu multimedia yang dilengkapi dengan alat pengontrol yang dapat dioperasikan oleh pengguna, sehingga pengguna dapat memilih apa yang dikehendaki untuk proses selanjutnya.

Konsep multimedia didefinisikan dalam banyak cara, bahwa multimedia berisi teks, grafik, animasi, video dan suara cara yang terintegrasi dan konten dapat terstruktur dan disajikan secara berbeda. Multimedia dapat dilihat sebagai alat pembelajaran dan sarana komunikasi. Dalam situasi belajar, produk multimedia dan layanan online dapat digunakan secara kreatif dan reflektif. Selain itu, multimedia dapat digunakan untuk mendorong subjek pembelajaran dan topik lintas-kurikuler. Tujuan umum pendidikan membingkai penggunaan multimedia dalam pendidikan[6]. Pembelajaran yang memanfaatkan teknologi informasi untuk membuat suasana belajar lebih interaktif dan menyenangkan bagi perserta didik menjadi alternatif dalam melakukan kegiatan belajar mengajar[7][8][9][10].

\subsection{Perancangan Use Case}

Perancangan Use Case untuk cara kerja aplikasi pembelajaran pengenalan dan menghitung pola bangun datar dapat dilihat pada Gambar 1.

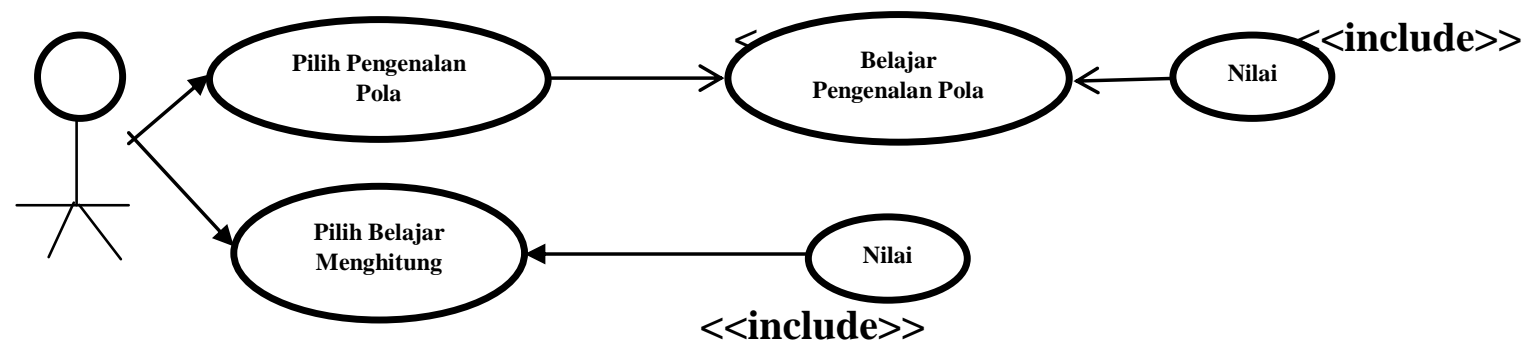

User

Gambar 1 Use case Media pembelajaran interaktif

User disini adalah anak TK Aba Surya Melati yang berinteraksi dengan sistem. User memilih apakah akan masuk kedalam sistem pengenalan pola atau belajar menghitung. Pada area 
pengenalan pola terdapat beberapa pola yakni: persegi, segitiga, oval, lingkaran, layang-layang, belah ketupat, trapesium, dan jajar genjang, disini anak TK Aba Surya Melati men-drag dan drop setiap pertanyaan yang akan didapatkan.

Sedangkan pada area belajar menghitung, anak diminta menjawab pertanyaan dengan cara menekan tombol button angka. Dari kedua pilihan menu ini terdapat suara, dan suara akan tampil untuk memastikan jawaban anak benar atau salah. Jika jawaban anak benar, maka akan mendapat nilai 1 (satu) dari setiap pertanyaan. Sebaliknya jika jawaban salah, maka anak mendapatkan nilai 0 (nol) dari setiap pertanyaan.

Soal yang disajikan memiliki keunikan soal tersendiri agar anak merasa tertarik dan berfikir, mengenal dan melatih kecerdasaan anak untuk mengenal pola dan menghitung bangun datar.

\subsection{Perancangan Tahap Animasi}

Tahap membuat animasi pada aplikasi ini dilakukan sebagai berikut :

\section{Konsep}

Pertama kali pembuatan media pembelajaran dikerjakan yakni persiapkan gambar beberapa bangun datar yang akan digunakan. Setelah mempersiapkan beberapa bangun datar yang akan digunakan, kemudian siapkan beberapa kebutuhan yang lainnya seperti aplikasi Adobe Flash professional CS6 sebagai pembuatan aplikasi media pembelajaran serta suara. Suara dibutuhkan agar media pembelajaran yang lebih interaktif dan menarik.

\section{Storyboard}

Storyboard dilakukan yaitu dengan cara membuat konsep dari awal sampai akhir. Setelah itu, kemudian letakkan beberapa kebutuhan data seperti gambar bangun datar dengan variasi warna. Suara dan gambar pesan akan dimunculkan jika pencocokan pola dan menghitung bangun datar adalah benar atau salah. Adapun latihan soal dan jumlah bangun datar yang dibutuhkan diberikan warna yang menarik, begitu pula warna dan gambar untuk background

\section{3. $\quad$ Take Voice \& Music Background}

Suara yang dihasilkan untuk pembuatan media pembelajaran interaktif pengenalan pola bangun datar dan belajar menghitung jumlah bangun datar digunakan suara pada setiap pengenalan bangun datar dengan cara merekam suara melalui Handphone. Kemudian suara dari rekaman tersebut di upload ke salah satu website online audio converter sehingga dapat digunakan pada media pembelajar interaktif. Tidak hanya dari audio yang digunakan pada media pembelajaran ini, suara musik juga digunakan sebagai pembuka aplikasi maupun pemberian suara pada setiap button agar lebih menarik perhatian user/ anak pada saat menjalankan aplikasi media pembelajara interaktif.

\subsection{Flowchart ActionScript}

Perancangan Flowcart ActionScript untuk proses jalannya sebuah program media pembelajaran interaktif pengenalan pola dan belajar menghitung. Adapun langka-langkah program (ActionScript) dari awal sampai akhir dapat dilihat pada gambar 2. 


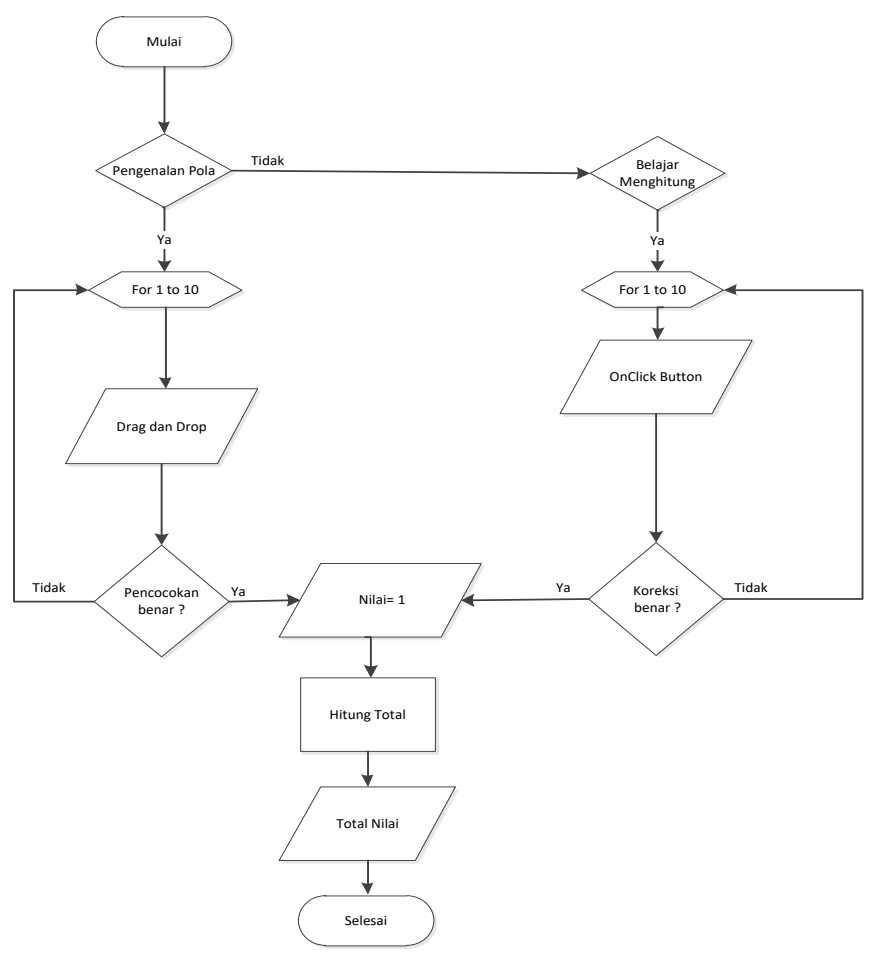

Gambar 2. Flowchart ActionScript Media Interaktif Pembelajaran

Pada Gambar 2 Flowchart ActionScript menunjukan proses kerja media interaksi pembelajaran dari ketika user membuka aplikasi, kemudian ditampilkan menu, setelah itu setelah itu memilih menu pengenalan pola dan belajar menghitung, dari salah satu pilihan tersebut ditampilkan beberapa bangun datar.

Jika memilih pengenalan pola, maka akan dikenalkan nama-nama bangun datar yang sudah sediakan didalam aplikasi disertai suara. Jika memilih belajar menghitung bangun datar, maka akan ditampilkan soal pertanyaan baik melalui teks maupun suara. Pertanyaan melaui suara akan membantu anak yang masih belum bisa membaca soal-soal pertanyaan. Soal bangun datar yang telah dijawab user/anak pertanyaan baik jawaban benar maupun salah, akan mendapat nilai 1 sampai dengan 10. Tombol button SELANJUTNYA akan mengganti soal berikutnya.

\section{Pengujian Dan Pembahasan}

\subsection{Pengujian}

Pengujian dari aplikasi media pembelajaran interaktif pengenalan pola dan belajar menghitung hasil dari rancangan dan penguji pada TK Aba Surya Melati sebagai berikut :

1. Tampilan Loading

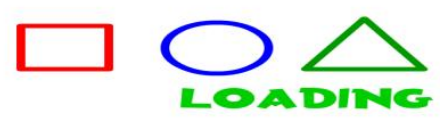

Gambar 3 Tampilan Loading

Tampilan Loading pada Gambar 3 menandakan bahwa aplikasi tersebut sudah berhasil dijalankan dan ketika Loading sudah selesai, maka aplikasi akan masuk ke dalam menu utama.

2. Tampilan Menu Utama 


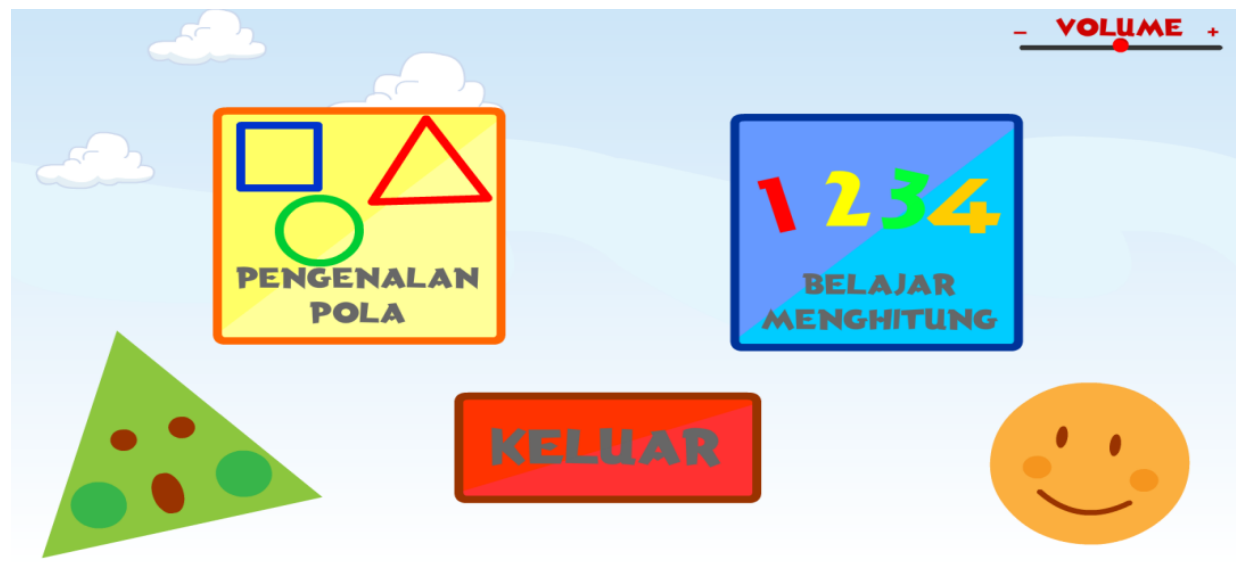

Gambar 4 Tampilan Menu Utama

Tampilan Menu Utama pada Gambar 4 terdapat beberapa pilihan menu dan terdapat elemen volume. Beberapa elemen menu diantaranya yaitu Pengenalan Pola, Belajar Menghitung dan Keluar. Jika pengenalan pola diklik, maka akan muncul informasi pengenalan pola bangun datar dapat dilihat pada gambar 5 dan kemudian menuju soal pertanyaan. Sedangkan elemen Volume berfungsi untuk mengatur besar dan kecilnya suara pada aplikasi tersebut. Elemen belajar berhitung bangun datar dapat dilihat pada gambar 8 dan juga disertai soal pertanyaan tentang jumlah bangun datar yang disajikan. Elemen KELUAR berfungsi untuk kelaur dari aplikasi.

3. Tampilan Informasi Pengenalan Pola

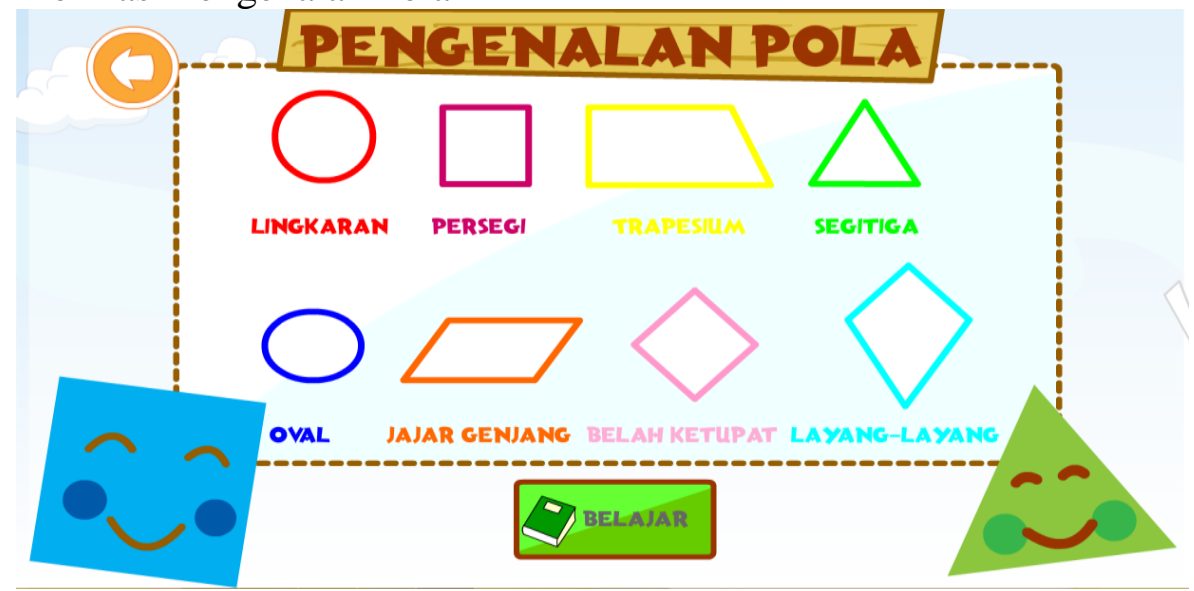

Gambar 5 Tampilan Informasi Pengenalan Pola

Tampilan Informasi Pengenalan Pola pada Gambar 5 memberi informasi tentang lingkaran, persegi, trapesium, segitiga, oval, jajar genjang, belah ketupat, layang-layang dari beberapa bangun datar, jika bangun datar ini diklik satu persatu, maka akan mengeluarkan suara yang akan dicocokan nantinya pada soal yang akan dikerjakan. Adapun Gambar 5 akan tampil jika sudah klik button BELAJAR untuk memulai soal pengenalan pola.

\section{Tampilan Soal Pada Pengenalan Pola.}

Tampilan Soal pada Gambar 6 terdapat beberapa pola yang akan dicocokan dengan cara menggeser pola kearah soal yang ada pada soal disebelah kiri. Jika pola tersebut telah di-drag dan drop, maka akan muncul button lanjut untuk melanjutkan soal berikutnya. Untuk lebih jelasnya dapat dilihat pada gambar 6 . 


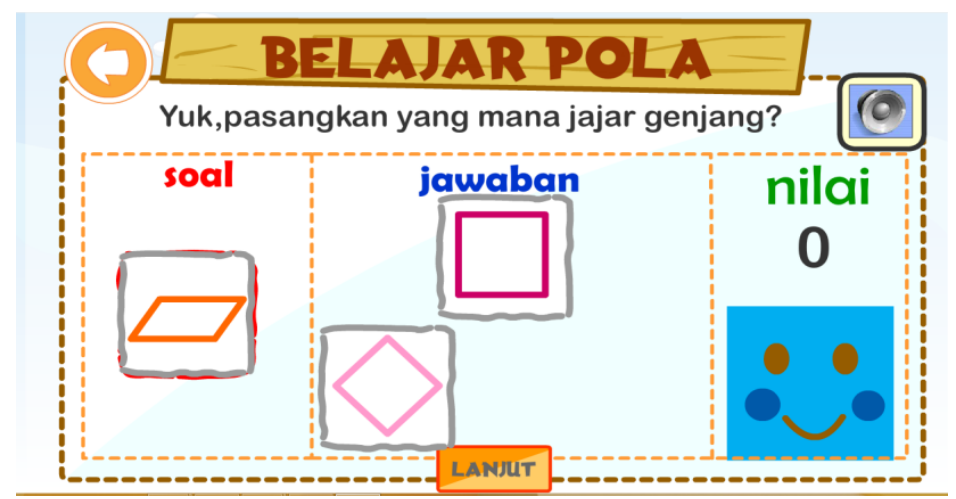

Gambar 6 Tampilan Soal pada pengenalan pola

\section{Tampilan Nilai}

Tampilan nilai pada Gambar 7 akan muncul jika semua soal sudah terjawab benar maupun salah. Jika ingin mengerjakan soal lagi, maka klik button panah yang terdapat pada area tersebut dan secara otomatis akan kembali ke menu utama.

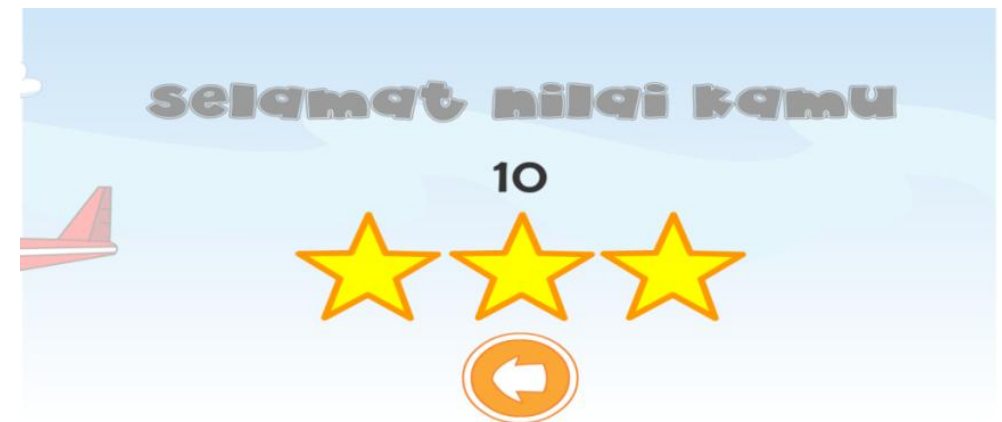

Gambar 7 Tampilan Nilai Pengenalan Pola

\subsection{Pembahasan}

1. Belajar Menghitung

Tampilan pada Gambar 8 terdapat beberapa soal untuk menghitung berapa jumlah bangun datar sesuai dengan pertanyaan yag diajukan. Macam-macam pola bangun datar divariasi dengan warna yang berfungsi untuk melatih konsentrasi anak. Jika anak sudah yakin pada jumlah pola bangun datar sesuai yang ditanyakan baik melalui teks dan suara, maka pilih button angka yang telah disediakan pada area jawaban.

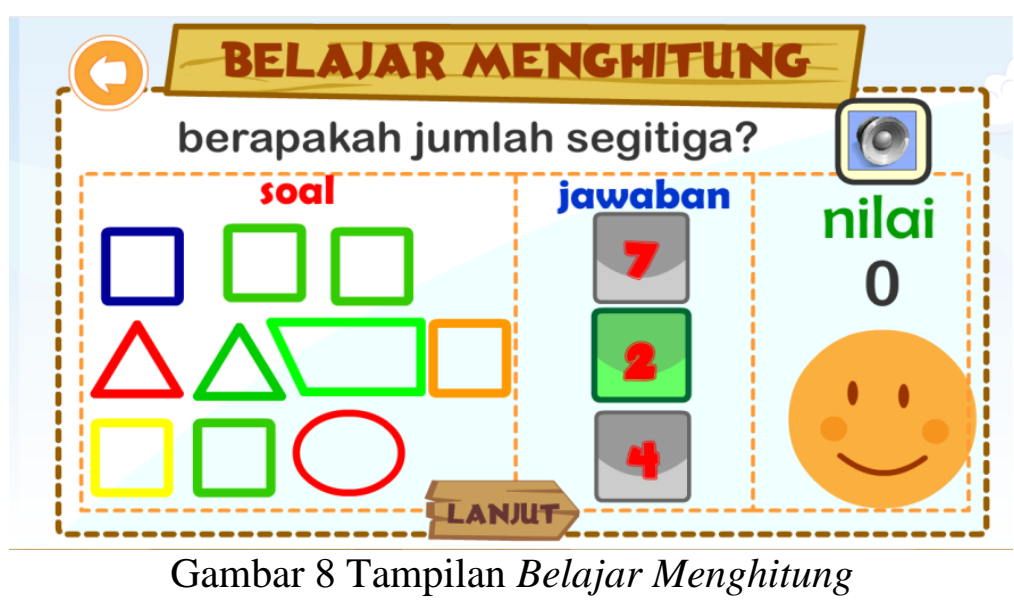




\section{Tampilan Nilai}

Tampilan pada Gambar 9 merupakan tampilan nilai yang akan tampil jika semua soal sudah terjawab benar maupun salah. Jika ingin mengerjakan soal kembali, maka mengklik button panah yang berfungsi untuk kembali ke menu utama secara otomatis. Jika ingin mengulang menjawab soal atau pertanyaan kembali agar lebih paham tentang cara menghitung dapat masuk kembali ke form belajar menghitung dan user atau anak dapat mengerjakan soal kembali.

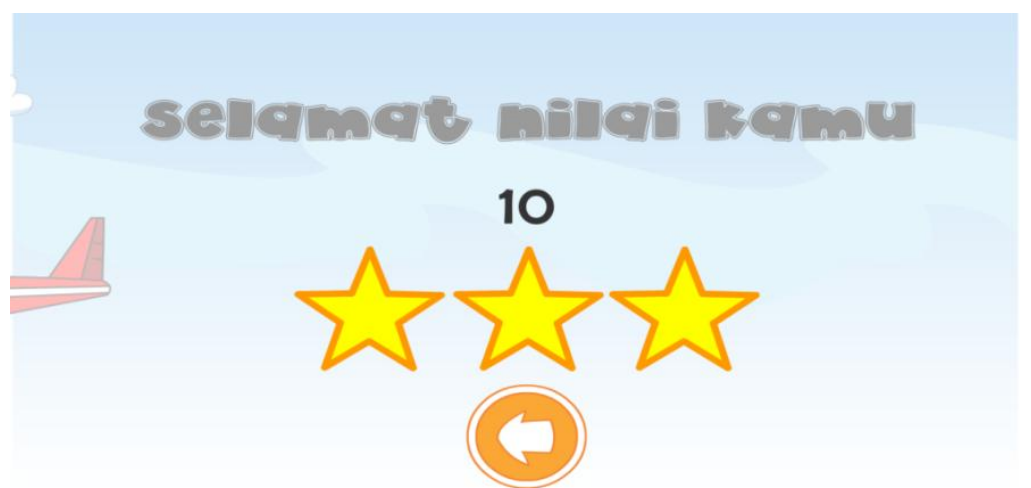

Gambar 9 Tampilan nilai Belajar Menghitung

Hasil Pengujian ini dilakukan dengan cara mendapatkan data nilai yang didapatkan oleh anak TK Aba Surya Melati dalam belajar mengenal pola bangun datar 2 dimensi ini dapat dilihat pada Tabel 1 .

Tabel 1 Pengambilan data nilai Pengenalan Pola

\begin{tabular}{|c|l|c|c|c|c|}
\hline No & Nama Lengkap & Usia & $\begin{array}{c}\text { Jenis } \\
\text { Kelamin } \\
\text { L/P }\end{array}$ & Kelompok & Nilai \\
\hline 1. & Andhika Farel Prasetya & 5 Tahun & L & B2 & 8 \\
\hline 2. & Diki Saputra & 5 Tahun & L & B2 & 8 \\
\hline 3. & Dinda Zaskia Putri Melati & 5 Tahun & P & B2 & 6 \\
\hline 4. & Muhammad Taufik & 5 Tahun & L & B1 & 6 \\
\hline 5. & Naila Salsabila Putri & 4 Tahun & P & B2 & 8 \\
\hline 6. & Naizar Fawwas Nur Ihsan & 5 Tahun & L & B2 & 9 \\
\hline 7. & Juno Bramantyo & 6 Tahun & L & B2 & 9 \\
\hline 8. & Muhammad Tegar Revandani & 5 Tahun & L & B2 & 9 \\
\hline 9. & Keysa Aurelia Azahra & 5 Tahun & P & B2 & 7 \\
\hline 10. & Ayu Aulia Febriana Khaerani & 5 Tahun & P & B1 & 6 \\
\hline 11. & Nafid Fauziah Nuriyadi & 4 Tahun & L & B1 & 9 \\
\hline 12. & Fani Maru'ah & 5 Tahun & P & B2 & 9 \\
\hline 13. & Khayla Zivania Khorunnisa & 5 Tahun & P & B2 & 7 \\
\hline 14. & Eva Listiyaningsih & 5 Tahun & P & B2 & 8 \\
\hline 15. & Ghaesani Azizan Setiawan & 6 Tahun & P & B2 & 8 \\
\hline 16. & Muthi'ah Zhahidah Aribah & 5 Tahun & P & B2 & 9 \\
\hline 17. & Annaya Hanam Rachmma Dian & 6 Tahun & P & B2 & 9 \\
\hline 18. & Rafa Septiano Pratama & 5 Tahun & L & B2 & 9 \\
\hline 19. & Geovana Letisia Irawan & 5 Tahun & P & B1 & 9 \\
\hline 20. & Azka Pragata & 5 Tahun & L & B1 & 9 \\
\hline & & & & \\
\hline
\end{tabular}




\begin{tabular}{|c|l|c|c|c|c|} 
21. & Ahmad Sandia Putra & 5 Tahun & L & B1 & 9 \\
\hline 22. & Meisya Laras Ayu & 5 Tahun & P & B1 & 8 \\
\hline 23. & Salsa Bila Nadhifa & 5 Tahun & P & B1 & 8 \\
\hline 24. & Virliy Mayyasa & 5 Tahun & P & B1 & 6 \\
\hline 25. & Queenra Callysta Yuri Putri & 4 Tahun & P & B1 & 6 \\
\hline 26. & Priska Aurelia & 4 Tahun & P & B1 & 7 \\
\hline 27. & Ashila Saffa Sulistyawati & 5 Tahun & P & B1 & 9 \\
\hline 28. & Fishelsah Iramadani Putri & 4 Tahun & P & B1 & 8 \\
\hline 29. & Julia Putri Nur Rahmadan & 5 Tahun & P & B1 & 8 \\
\hline 30. & Arsa Ardiansyah & 6 Tahun & L & B1 & 9 \\
\hline
\end{tabular}

Cara Perhitungan :

$$
\frac{\text { Total Nilai }}{\text { Jumlah Soal }} \boldsymbol{X 1 0 0} \%=\text { Hasil }
$$

Hitung $=\frac{\mathbf{2 4 0}}{\mathbf{3 0 0}} \boldsymbol{X 1 0 0} \%=80 \%$

Hasil perhitungan untuk belajar mengenal pola diperoleh hasil $80 \%$.

Hasil yang didapatkan melalui pengujian pada anak TK Aba Surya Melati dalam belajar menghitung pola bangun datar 2 dimensi ini dapat dilihat pada Tabel 2.

Tabel 2 Pengambilan data nilai Belajar Menghitung

\begin{tabular}{|c|c|c|c|c|c|}
\hline No & Nama Lengkap & Usia & $\begin{array}{c}\text { Jenis } \\
\text { Kelamin } \\
\text { L/P }\end{array}$ & Kelompok & Nilai \\
\hline 1. & Andhika Farel Prasetya & 5 Tahun & $\mathrm{L}$ & $\mathrm{B} 2$ & 7 \\
\hline 2. & Diki Saputra & 5 Tahun & $\mathrm{L}$ & $\mathrm{B} 2$ & 7 \\
\hline 3. & Dinda Zaskia Putri Melati & 5 Tahun & $\mathrm{P}$ & B2 & 5 \\
\hline 4. & Muhammad Taufik & 5 Tahun & $\mathrm{L}$ & $\mathrm{B} 1$ & 4 \\
\hline 5. & Naila Salsabila Putri & 4 Tahun & $\mathrm{P}$ & $\mathrm{B} 2$ & 7 \\
\hline 6. & Naizar Fawwas Nur Ihsan & 5 Tahun & $\mathrm{L}$ & $\mathrm{B} 2$ & 7 \\
\hline 7. & Juno Bramantyo & 6 Tahun & $\mathrm{L}$ & $\mathrm{B} 2$ & 7 \\
\hline 8. & Muhammad Tegar Revandani & 5 Tahun & $\mathrm{L}$ & $\mathrm{B} 2$ & 7 \\
\hline 9. & Keysa Aurelia Azahra & 5 Tahun & $\mathrm{P}$ & $\mathrm{B} 2$ & 5 \\
\hline 10. & Ayu Aulia Febriana Khaerani & 5 Tahun & $\mathrm{P}$ & $\mathrm{B} 1$ & 7 \\
\hline 11. & Nafid Fauziah Nuriyadi & 4 Tahun & $\mathrm{L}$ & B1 & 6 \\
\hline 12. & Fani Maru'ah & 5 Tahun & $\mathrm{P}$ & $\mathrm{B} 2$ & 8 \\
\hline 13. & Khayla Zivania Khorunnisa & 5 Tahun & $\mathrm{P}$ & $\mathrm{B} 2$ & 5 \\
\hline 14. & Eva Listiyaningsih & 5 Tahun & $\mathrm{P}$ & $\mathrm{B} 2$ & 7 \\
\hline 15. & Ghaesani Azizan Setiawan & 6 Tahun & $\mathrm{P}$ & $\mathrm{B} 2$ & 6 \\
\hline 16. & Muthi'ah Zhahidah Aribah & 5 Tahun & $\mathrm{P}$ & $\mathrm{B} 2$ & 7 \\
\hline 17. & Annaya Hanam Rachmma Dian & 6 Tahun & $\mathrm{P}$ & $\mathrm{B} 2$ & 8 \\
\hline 18. & Rafa Septiano Pratama & 5 Tahun & $\mathrm{L}$ & $\mathrm{B} 2$ & 8 \\
\hline 19. & Geovana Letisia Irawan & 5 Tahun & $\mathrm{P}$ & $\mathrm{B} 1$ & 7 \\
\hline 20. & Azka Pragata & 5 Tahun & $\mathrm{L}$ & B1 & 5 \\
\hline 21. & Ahmad Sandia Putra & 5 Tahun & $\mathrm{L}$ & B1 & 8 \\
\hline 22. & Meisya Laras Ayu & 5 Tahun & $\mathrm{P}$ & $\mathrm{B} 1$ & 6 \\
\hline
\end{tabular}




\begin{tabular}{|l|l|c|c|c|c|} 
23. & Salsa Bila Nadhifa & 5 Tahun & P & B1 & 8 \\
\hline 24. & Virliy Mayyasa & 5 Tahun & P & B1 & 5 \\
\hline 25. & Queenra Callysta Yuri Putri & 4 Tahun & P & B1 & 6 \\
\hline 26. & Priska Aurelia & 4 Tahun & P & B1 & 5 \\
\hline 27. & Ashila Saffa Sulistyawati & 5 Tahun & P & B1 & 7 \\
\hline 28. & Fishelsah Iramadani Putri & 4 Tahun & P & B1 & 6 \\
\hline 29. & Julia Putri Nur Rahmadan & 5 Tahun & P & B1 & 6 \\
\hline 30. & Arsa Ardiansyah & 6 Tahun & L & B1 & 8 \\
\hline
\end{tabular}

Cara Perhitungan :
Hitung $=$
$\frac{195}{300} X 100 \%=65 \%$

Hasil Perhitungan untuk belajar menghitung pola bangun datar didapatkan hasil $\mathbf{6 5 \%}$.

\section{Kesimpulan} berikut :

Berdasarkan hasil dari pembahasan dan pengujian, maka dapat diambil kesimpulan sebagai

1. Aplikasi media pembelajaran interaktif pengenalan pola bangun datar dan belajar menghitung bangun datar berhasil diimplementasikan dan dijalankan sesuai dengan perancangan.

2. Aplikasi media pembelajaran interaktif diujikan di TK Aba Surya Melati dengan responden sebanyak 30 siswa, berdasarkan pengujian pengenalan pola bangun datar tingkat keberhasilan siswa mengerjakan soal adalah $80 \%$, sedangkan pada pengujian belajar menghitung pola bangun datar tingkat keberhasilan siswa mengerjakan soal $65 \%$.

\section{Daftar Pustaka}

[1] Nomor, P. P. R. I. (27). Tahun 1990 tentang Pendidikan Prasekolah.

[2] Fa'uni, A. M. (2014). Meningkatkan Kemampuan Matematika Sederhana Melalui Permainan Geometri Pada Anak Kelompok A RA Al Islam Kadipiro Sambirejo Sragen Tahun Ajaran 2013-2014 (Doctoral dissertation, Universitas Muhammadiyah Surakarta).

[3] Kustiawan, U. (2016). Pengembangan Media Pembelajaran Anak Usia Dini. Penerbit Gunung Samudera [Grup Penerbit PT Book Mart Indonesia].

[4] Firmantoro, K., Anton, A., \& Nainggolan, E. R. (2016). Animasi Interaktif Pengenalan Hewan Untuk Pendidikan Anak Usia Dini. Jurnal Techno Nusa Mandiri, 13(2), 14-22.

[5] Faroqi, A., \& Maula, B. (2014). Aplikasi Multimedia Interaktif Pembelajaran Membaca, menulis, berhitung (calistung). JURNAL ISTEK, 8(2).

[6] Andresen, B. B., \& van den Brink, K. (2002). Multimedia in education. In Infarmation technologies at school: conference materials.

[7] Retnowati, N. D., \& Rahmawan, M. G. (2016). Animasi E-learning Pembelajaran Matematika dan Fisika Bagi Siswa Sekolah Menengah Pertama Kelas 1. Angkasa: Jurnal Ilmiah Bidang Teknologi, 8(2), 139-148.

[8] Wintolo, H., \& Widiastuti, A. T. (2015). Pemanfaatan Image to Speech Berbasis Android Untuk Pengenalan Warna Bagi Anak Bawah Tiga Tahun (Batita). Angkasa: Jurnal Ilmiah Bidang Teknologi, 7(2), 1-12.

[9] Pratama, D. F., Tamatjita, E. N., \& Nugraheny, D. (2016). Permainan Catur Inggris Berbasis Android Menggunakan Algoritma Minimax. Compiler, 5(2).

[10] Tamatjita, E. N., Irawaty, M., \& Ramdhani, R. (2016). Sistem Pakar Pada Permainan Untuk Mengukur Tingkat Intelligence Quotient (Iq) Menggunakan Metode Binet-simon Berbasis Android. Compiler, 5(1). 